. ร.

JULY 1975 TO DECEMBER 1975

Submitted to the Bureau of Land Management

By Robert D. Ohmart

Prepared by: R.F. Seegmiller, R.D. Ohmart and S.L. Woodward

Department of Zoology, Arizona State University

Tempe, Arizona 85281

SF

361.73

. A6

036

1976
BLM Library

Denver Federal Center

Bldg. 50, OC-521

P.O. Box 25047

Denver, CO 80225

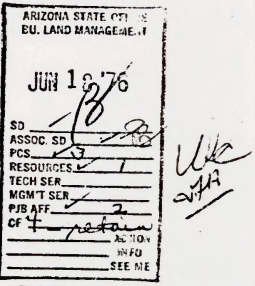


$\because$ 
The Chemehuev1, B111 Williams and Kofa Mountains are presently serving $\because \quad i_{1}, \ldots \cdots, \cdots$

as study areas to examine the blology of wild burros (Equus asinus). This

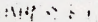

research includes an investigation of burro-bighorn sheep (Ovis canadensis) (A) $A$ wint

Interactions in the B111 Williams and Kofa Mountalns.

\section{Chemehuev1 Mountains}

Dr. Woodward is intermittently monitoring movements, habitat use, food habits and reproduction of the burro herd.

Two papers have been submitted to scientific journals on our previous findings. One on habitat use and diet has been accepted for publication In the Journal of Range Management (copy appended) and the other on home ranges and movements is being readied for submission to the Journal of Wildife Management. A copy of Susan's doctoral thesis will be submitted to BLM as soon as my office receives one.

Recently three of our marked burros were found shot to death in Trampas Wash.

\section{B111 Williams Mountains}

Mr. Rick Seegmiller has completed his field studies on sheep and burros, and an abstract of his findings are included in this report. Mr. Mike Walker will continue the study and has already begun observing both species and collecting monthly fecal samples for diet determinations. Rick's thesis should be completed in the next few months and will be included in the next report.

Approximately eight months of field research were conducted during the summer of 1974 and the winter, spring, and early summer of 1975. Data regarding the relationships of feral burros and desert bighorn sheep, as to their movements, food habits, and interspecific interactions were recorded.

The monitoring of burro and bighorn movements was aided with seven radio-transmitter collars on burros and one on a ewe bighorn sheep. Color 
collars were also attached to sixteen burros, allowing definitive identifi-

cation of thesè indlvia_uls. Observations were made pr. ipally in the B111

.

Williams Mountain block, fust east of the Bill Williams River Delta at

Lake Havasu, Arizona.

Burro movements during sumfer followed a consistent daily pattern. The dixytime hours were spent in the foothills and washes. Movements were made to the riparian communities in the late evening or night and back to the desert in the early morning hours. During the cooler months, no consistent movement pattern was observed and only sporadic treks were made to the river.

The distribution of burros and bighorn sheep (Figures 1,2 and 3) varied seasonally in amount of overlap and proximity to permanent water. Substantial overlap was observed during all seasons, but was greatest during November to March, when the area occupied by burros completely encompassed that of bighorn sheep.

Table 1 illustrates the seasonal mean distance of burro and bighorn sightings from the Bill williams River or other permanent water sources adjacent to the river. Both species remained in relatively close proximity to permanent water during the warmer months (May to August). In the cooler months, October to April, sporadic rains supplied temporary free water and succulent annual vegetation, allowing burros and bighorns to venture farther from permanent water.

Types of habitats preferred by burros and bighorns for forage intake were determined by first differentiating the study area into seven major categories: foothills, long steep slopes, rugged talus terrain, mesas, washes, cultivated flelds, and riparian. Table 2 shows the percent frequency of burro and bighorn sightings in these habltat types, over the total distribution of each species and within the area of distribution overlap. To gain insight into habitat overlap between burros and bighorn sheep, the habitat preferences of each species within the area of distribution overlap becomes especially important. Within this area, greatest overlap 


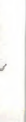


- FIGURE 1. DISTRIBUTION OF BURRO AND BIGHORN HERD LOCATIONS

IN THE BILL WILLIAMS MOUNTAINS: JUNE-OCTOBER 1974

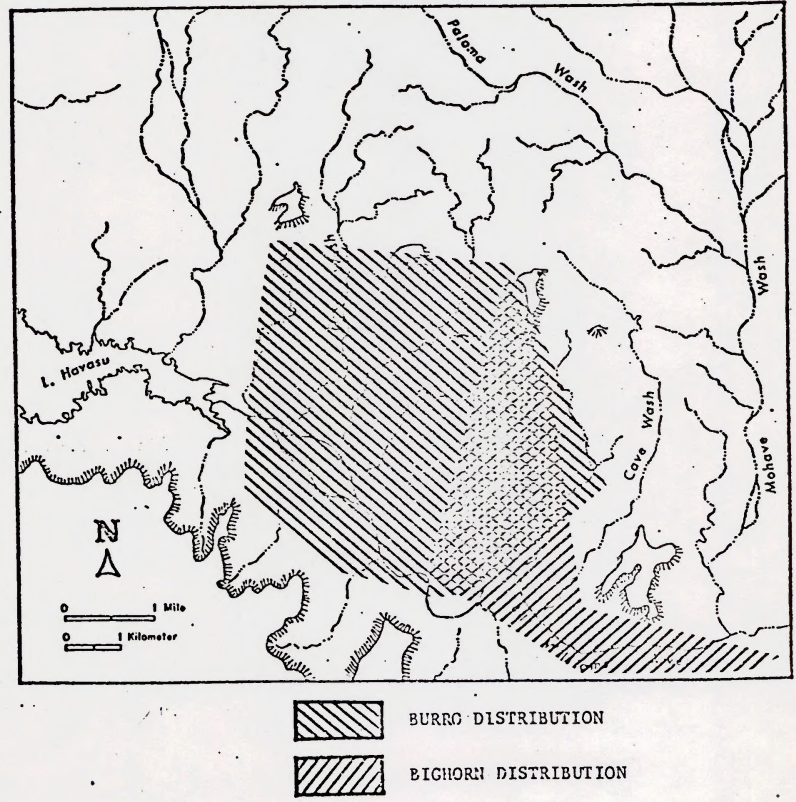




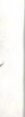



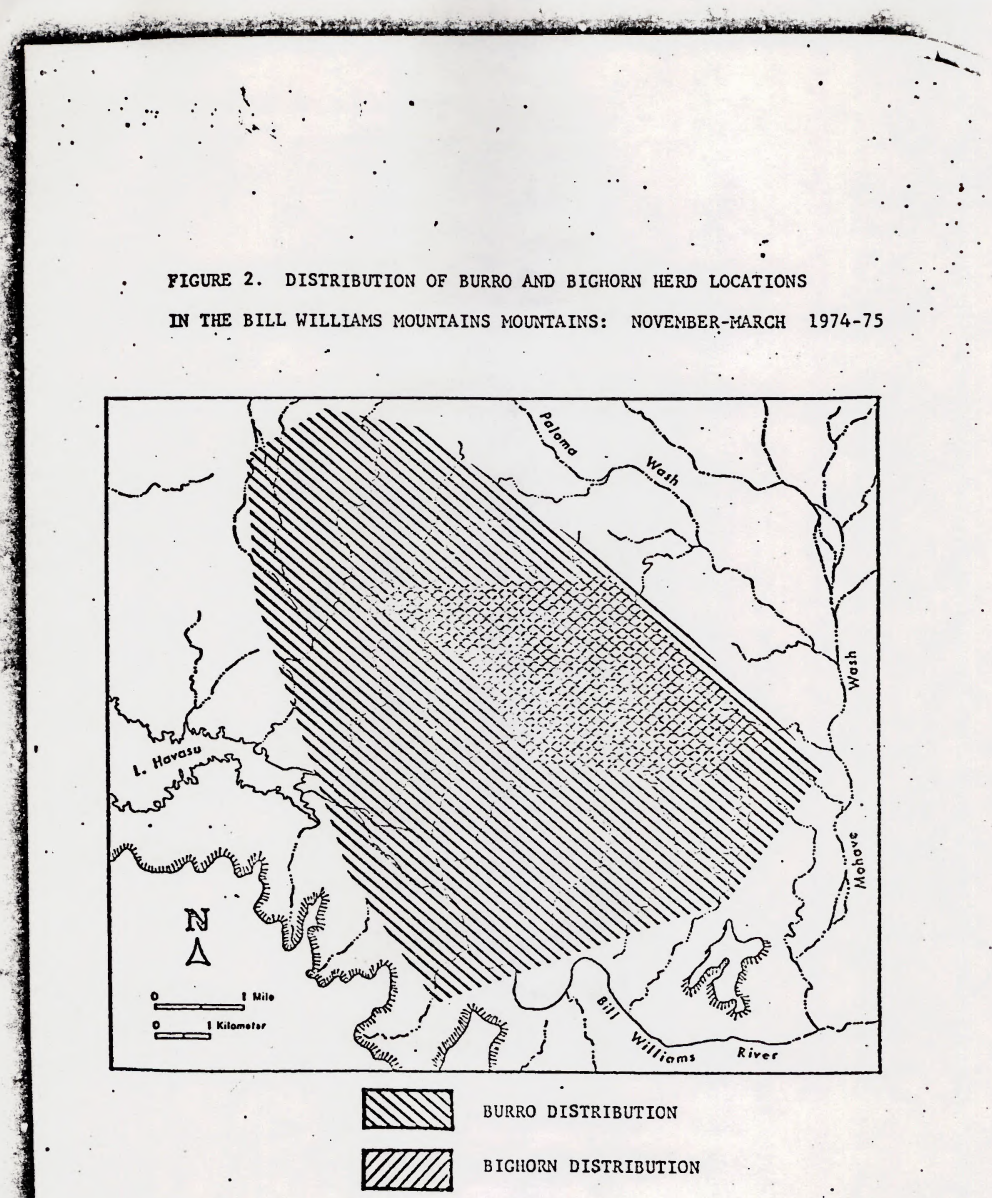
-

。 
- FIGURE 3. DISTRIBUTION OF BURRO AND BIGHORN HERD LOCATIONS

IN THE BILL WILLIAMS MOUNTAINS: APRIL-JUNE 1975

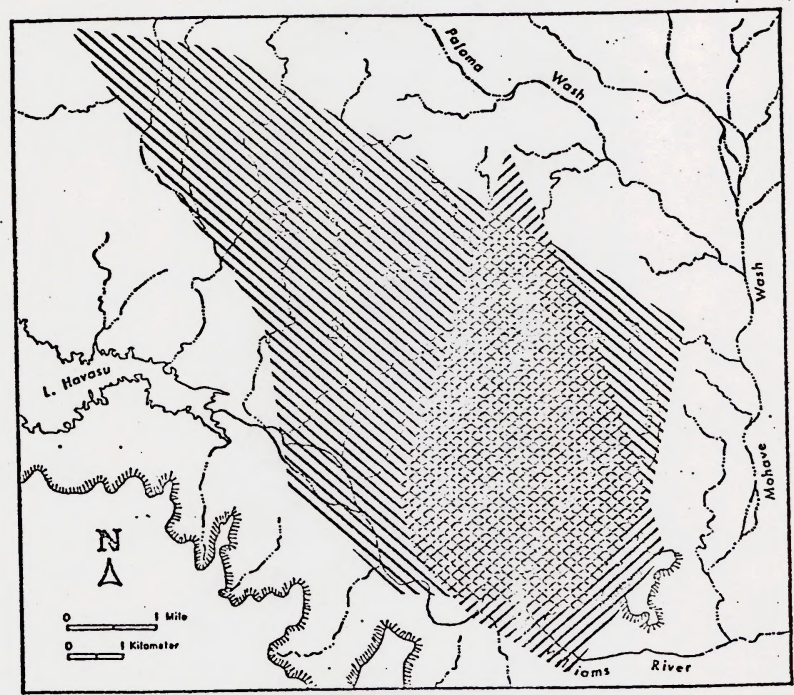

DIIIV BURล' DISTRIBUTION

QDIDA BIGLURN DISTRIBUtion 

Table 1. SEASONAL MEAN DISTANCE OF BURRO AND BIGHORN SIGHTINGS FROM THE BILL WILLIAMS RIVER OR OTHER PERMANENT WATER SOURCES

Mean Distance (miles):

Range of Distance (m1les):

Number of Sightings:

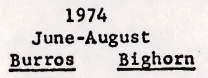

0.65

0.00

2.50

$$
\begin{aligned}
& 0.00- \\
& 3.00
\end{aligned}
$$

0.25 -

$$
3.25
$$

$2.00-$
4.25

$0.00-$

$$
4.00
$$

$0.50-$

4.25

$0.25-$

2.50

c.00-

1.75

$$
\pm 0.04
$$

$\pm 0.08$

161

1253

280

33

491

156

366

137

\footnotetext{
* Kay not be true representation in that only casual observations were made of bighorn sheep
} mostly around water or cultivated fields. 
4

• 
-

Table 2: : . PERCENT FR ENCY OF BURRO AND BIGLORN SIGH ' VGS

'IN VARIUUS TYPES OF TOPOGRAPHY OR HABIT...

Habitat or

Topography Type

Foothills

Long Steep Slopes

Rugged Talus Terrain

Washes

1974

Over Total Distribution

June-October

November-March

April-June

Burros Bighorn Burros Bighorn Burros Bighorn

Mesas

Cultivated Fields

59

49

55

0

76

36

3

1

33

67

4

15

0

4

21

0

13

31

0

9

0

19

5

0

0

12

0

7

5

39

1

0

1

24

Riparian

Total

$\frac{2}{100}$
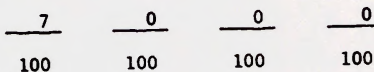

100

100

100

Number of Sightings

1323

168

576

150

570

169

Within Area of Distribution Overlap

Habitat or

Topography Type

Foothills

Long Steep Slopes

Rugged Talus Terrain Burros

57

Bighorn

Bu

urros

0

$$
26
$$

38

Bighorn

Burros Bighorn

Washes

0

3

44

0

61

50

$26^{\circ} \quad 0$

0

67

4

13

$0 \quad 0$

13

21

0

6

Mesas

17

59

5

12

. 30

7

Cultivated Fields

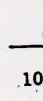

Number of Sightings

89

0

$\frac{0}{100}$

61

0

0

5

21

Riparian

Total

00

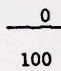

$\frac{0}{100}$

215

150

158

$\frac{0}{100}$

100

130 
- In topography occurred 'ring November to March on long - eep slopes

extending from high mesas, peaks, and ridges (burros $44 \%$; bighorns $67 \%$ ) and during April to June in foothill topography (burros $61 \%$; bighorns $50 \%$ ). Foothills were generally choppy, 'rolling, or flat interfluves of relatively low elevation.

The ten major plant species in the dlets of burros and bighorn sheep on an average annual basis and as determined by fecal composition analysis 1s shown in Table 3. The predominant plant in the diets of both was the annual forb indian-wheat, (Plantago insularis), $26 \%$ in burro diets and $16 \%$ in bighorn diets. Of the ten major plants, burros and bighorns shared bermuda grass, (Cynodon dactylon), foothills palo verde, (Cercidium microphyllum), burro-bush, (Ambrosia dumosa), brittle-bush, (Encelia farinosa), and forget-me-not, (Cryptantha spp.).

The monthly utilization of the three major plant species shared in the diets of burros and bighorns, Indian-wheat, palo verde and bermuda 8 rass, is represented in Figure 4. Both species foraged on Indian-wheat principally in the winter and spring when it was abundant. Palo verde was taken primarily in summer and winter and bermuda grass predominantly in the sumer, the latter coinciding with its growing season. Generally, these three plant species were found in a higher proportion in the diet of burros than in bighorn sheep.

Burros when foraging palo verde, rather than selecting a portion of the annual new growth at the branch tips as bighorn and most other browsing animals do, generally chew and break off branches up to six feet in length and $1 \frac{1}{2}$ inches in diameter. They then shred and consume a small portion of the broken end of the branch and leave the remainder. As the lower branches of the palo verde are broken from the tree and partially consumed by burros the higher branches may be above the foraging ruach of sheep in areas of burro-bighorn distribution overlap and thereby reduce the avallability of 
Table 3. THE TEN MAJOR $M$ ANT SPECIES IN THE DIETS OF FERAT, BURROS AND

DESERT BIGHORA IIEEP IN THE BILL WILLIAWS IOUN. NS:

Fecal Composition Analysis.

\section{BURROS}

Plant Species

* Average \%

Relative Density $\quad \star \star *$ Frequency

1. Ind Ian-wheat-Plantago insularts

26

18

15

10

5

5. Arrow-weed-Pluchea sericea

6. Bulrush-Scirpus Olneyi

7. Staghorn Cholla-0puntia acanthocarpa

8. Burro-bush-Ambrosia dumosa

9. Brittle-bush-Encelia farinosa

10. Forget-me-not-Cryptantha spp.

100

100

3. Mesquite-Prosopis juliflora

microphyllum

4

3

2

2

1

100

100

78

44

89

78

89

100

\section{BIGHORN}

1. Indian-wheat-plantago insularis

100

2. Globe-mallow-Sphaeralcea Spp.

100

3. Desert-lavender-Hyptis Emoryi

8

100

4. Foothills Palo Verde-Cercidium microphvllum

7

100

5. Bermuda Grass-Cynodon dactylon

7

78

6. Forget-me-not-Cryptantha Spp.

100

7. Burro-bush-Ambrosia dumosa

6

89

8. Brittle-bush-Encelia farirosa

9. Burro-brush-Hymenoclea spp.

10. Creosote-bush-Larrea divaricata

*Average from months sampled, June 1974 through May 1975 (excepting September, November and December).

**Percent Frequency refers to the proportion of months sampled in which the plant species occurred in the diets. 


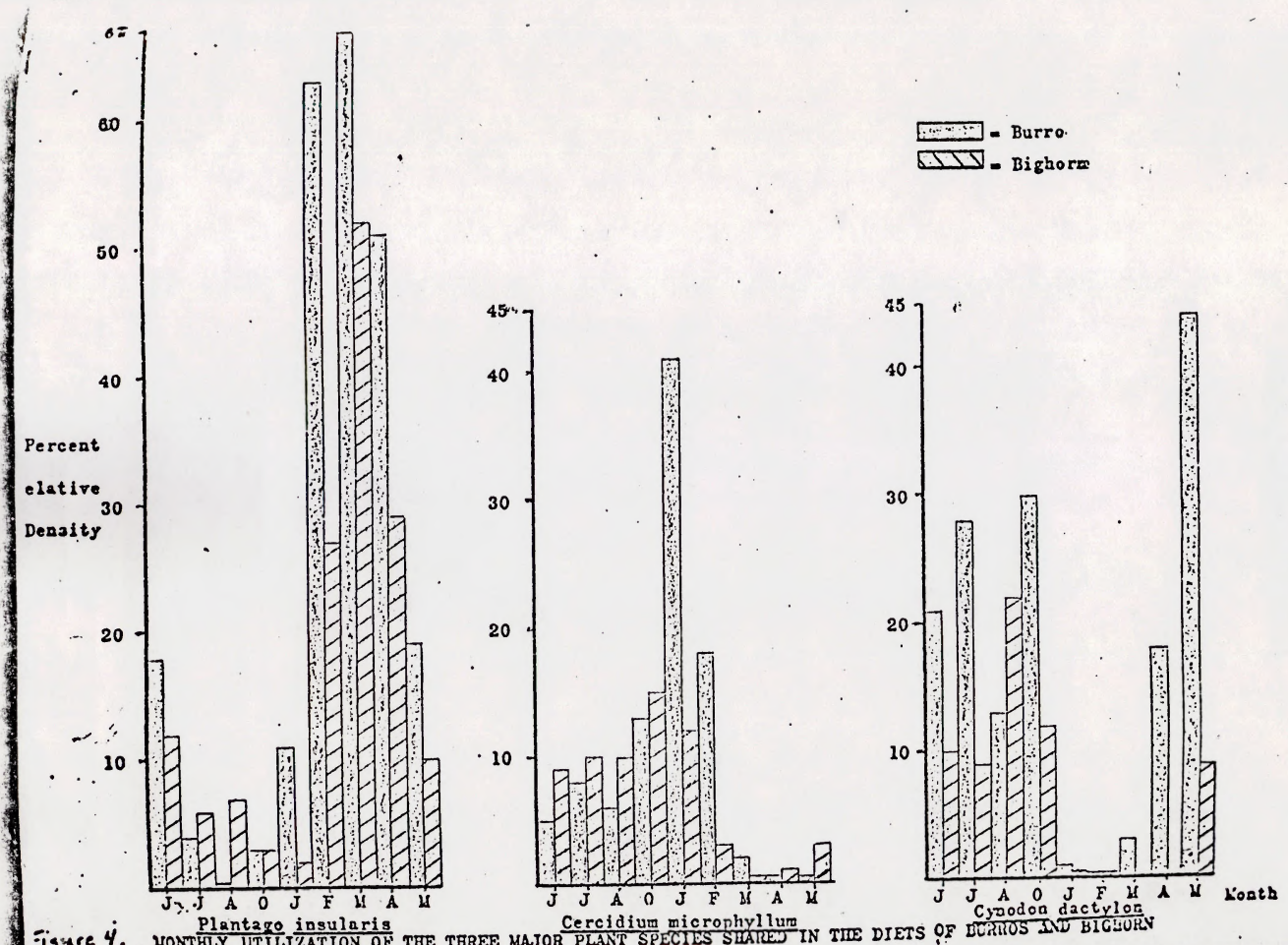

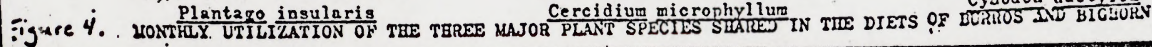


this Important browse sp es to sheep. The bark of pall erde is also taken by burros.

Burro-bighorn interactions at watering sites in summer were not observed and are probably unlikely since water is not limiting on the study area, due to the presence of the river and irrigation of the ffelds cultivated. by the Planet Ranch. In addition bighorn sheep watered during all hours of the day, contrasting to the nocturnal watering habit of burros.

On January 28th the first newborn lamb was observed with its maternal parent and other adult sheep in a high remote area. Between the dates of January 29 and February 2, the radio collared ewe gave birth to a lamb. Shortly before, during, and after lambing she and other bighorns were located only in the more rugged and remote terrain. They soon moved to the lower and less rugged areas that supplied more plentiful forage, principally the long steep slopes.

Burro-bighorn interactions during the lambing season were not observed and neither burros nor burro sign was observed in these isolated and rugged areas. However, shortly after lambing, both species were seen in close association, even with young lambs present. They showed seemingly no concern for one anothers presence.

Seasonal burro population ground estimates were made essentially by a direct count of marked, recognizable, and non-recognizable individuals. These generally indicated that approximately 100 burros used the study area, which varied seasonally in size from about 10 to 20 square miles. However, this estimate includes some burros that were infrequently seen and who apparently seldom visited the study area.

A total of 20 jennys with newborn foals were observed on the study area, yielding an estimated annual increment in the burro population of about $20 \%$. Natural mortality of foals was never seen or evidenced, suggesting high young survival in burros. 


$$
\text { . }
$$


A minimum of 15 adults and yearling bighorn sheep (this fig:are is thought to be a close $a_{k}$ coximation of the actual sheep. pulation in the area) were seen on the study area during January to April. Following this perlod none of the four adult ranş were observed until June (initiation of the breeding season), when several were again seen on the study area.

Three lambs were produced among seven aduit ewes, but by June two lambs were missing and were presumed dead. The third has survived into January 1976 suggesting an estimated 7\% annual bighorn population increase.

Recent visits to the study area in December and January showed nearly all palo verdes and most shrubs, especially near the river, to be heavily utilized. The cured herbaceous layer has been depleted over most of the area and succulent annual plant growth was not present.

Considering the current deteriorating range condition in the Bill Williams Mountains and the possibility of insufficient winter precipitation to propagate replenishment of the depleted winter annuals, future range conditions may be critical to both burros and bighorn sheep. This inturn, may lead to increased burro and bighorn use of the Planet Ranch cultivated fields. Continuing burro-bighorn research will be fundamental in assessing these effects on the bighorn sheep and the rapidly expanding burro population.

Kofa Mountains

In July 1975 a total of 20 burros were collared and marked with ear tags. Color collars were put on 13 animals and radio collars were placed on 7 . Susan Woodward has been monitoring the movements and reproductive success of this population. However, it appears that we will abandon this area and establish a new study area in the Black Mountalns. 
